\title{
Intentionality in Academic Telesupervision: A Phenomenological Study of Faculty Telesupervisors' Experiences
}

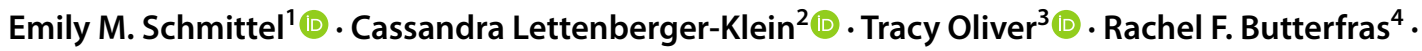 \\ Darren W. Adamson ${ }^{5}$ (D)
}

Accepted: 29 July 2021 / Published online: 7 August 2021

(c) The Author(s), under exclusive licence to Springer Science+Business Media, LLC, part of Springer Nature 2021

\begin{abstract}
In response to the COVID-19 pandemic and a widespread shift to telehealth, there is an increased need to understand how we can best provide Telesupervision (TS). To help address the limited research on TS in the Marriage and family therapy (MFT) field, the present study seeks to describe the experiences of faculty telesupervisors who have provided TS as part of an online COAMFTE Accredited MFT master's program since 2012 (telesupervision was provided before accreditation since 2005). Eighteen participants completed individual interviews or focus groups, which were analyzed using descriptive phenomenological procedures. Our results describe the essential structure of faculty supervisors' experiences providing TS. Core themes include: general experiences with TS as a modality, online university-specific experiences with TS as a modality, a systemic lens is intentionally applied, diversity, equity, and inclusion (DEI) are intentionally addressed, and clinical competencies and ethics are intentionally addressed. A discussion of the essential experiences of faculty TS along with implications for clinical training and future research are reviewed.
\end{abstract}

Keywords Telesupervision $\cdot$ Telehealth $\cdot$ Online MFT training $\cdot$ MFT faculty experience

\section{Intentionality in Telesupervision: A Phenomenological Study of Academic Telesupervision}

Over the last 15 years, distance-based programs have become more common not only in Marriage and family therapy (MFT), but across mental health professions, with Telesupervision (TS) being a component of training students in core skills. Additionally, in 2020, due to the COVID-19 pandemic, many MFTs in training and their

Emily M. Schmittel

eschmittel@ncu.edu

1 Department of Marriage and Family Sciences, Northcentral University (NCU), Springfield, MO, USA

2 Department of Marriage and Family Sciences, Northcentral University (NCU), Avon, OH, USA

3 Department of Marriage and Family Sciences, Northcentral University (NCU), Hollywood, FL, USA

4 Department of Marriage and Family Sciences, Northcentral University (NCU), Abilene, TX, USA

5 Department of Marriage and Family Sciences, Northcentral University (NCU), Cedar Hills, UT, USA supervisors were forced to move from in-person to TS to maintain oversight of clinical training and continuity of care. Brick and mortar MFT programs were also tasked with transitioning both clients and MFT training to virtual platforms. These changes occurred quickly and with minimal understanding about the nuances of how MFT supervision and training may look different in an online setting. As COAMFTE and state licensing boards update standards to allow for the use of TS to meet graduate program and licensure requirements, along with the growth of distance-based programs, there is an urgent need to understand experiences with TS including the strengths and limitations. Our online MFT Master's program has been providing TS to MFT students for 15 years and will continue to do so after the COVID-19 pandemic has resolved. As a result, we have methodically approached the implementation of supervision and have refined our efforts based on years of experience and feedback from various stakeholders. Our hope is that this qualitative investigation of our procedures can support other programs who have had to quickly shift to TS due to the pandemic. Specifically, this study seeks to better understand our online COAMFTE accredited MFT program's faculty 
supervisors' experiences with TS. To date there has been limited research on marriage and family therapy distanceeducation in general with recent calls to address this gap that exists in comparison to other mental health professions such as professional counseling and social work (Harrison, 2021). With TS being a key piece of distancebased MFT programs, this study also seeks to contribute to the literature on distance-based education in MFT. Additionally, the implications of this study can help inform supervision practices of other mental health professionals.

\section{Supervision in Marriage and Family Therapy Training}

MFT supervision is accepted as one of the most essential components in assisting new trainees in developing the skills and competencies of an ethical systemic practitioner. Although there is limited research on how supervision actually affects trainees and client outcomes (Nelson \& Graves, 2011), as an industry we believe supervision helps trainees transform theoretical knowledge into real-world clinical skills. Occurring as part of the clinical training portion of a degree and as part of a post-graduation state licensure requirement, supervision takes place in both individual and group formats. In the field of MFT, supervisors specifically provide systemically-oriented supervision which has been explained as having four core aspects (Todd \& Storm, 2014): (a) contextualizing supervision, (b) consideration of how a web of relationships, including the supervisor-supervisee relationship, influence client outcomes, (c) a systemic orientation to change processes, and (d) accountability to supervise development, the supervisory relationship, and client safety. Through their systemic approach, MFT supervisors guide trainees in developing clinical competencies such as: (1) Admission to treatment, (2) Clinical assessment and diagnosis, (3) Treatment planning and case management, (4) Therapeutic interventions, (5) Legal issues, ethics and standards, and (6) Research and program evaluation (AAMFT, 2004). Woven throughout these domains are ways in which MFTs promote Diversity, equity, and inclusion (DEI) in clinical practice. As we reflect on the purpose of MFT supervision and the sudden shift to much of it being provided through TS, it leaves us asking how our online program, which has been providing TS for years, can support our profession in making this shift. Some of the questions we ask include: What it is like for MFT faculty supervisors to provide MFT training through TS? Are they experiencing benefits to this delivery method that can be disseminated to the MFT field? Are they experiencing drawbacks that need to be better understood in order to ensure faculty TS is effective?

\section{Research on Telesupervision}

While limited research exists on TS, what we know about the benefits and best practices of TS aligns with adult learning theory (e.g., Knowles, 1980) and research on distance-based education for mental health professionals (Snow et al., 2018). The MFT field has generated little research on distance-based education, yet we can draw from the findings of multiple studies produced by similar fields such as social work and counselor education (Harrison, 2021).

In 2015, Blumer et al. highlighted the rise in the use of technology in family therapy practice and illustrated that MFTs have little training in using technology not only in therapy, but also for providing supervision. MFTs in their study responded in support of graduate training programs implementing more education on using technology in practice and supervision. Their participants were also interested in learning more about online technological practices, what specific technologies can be used, how to develop relationships in an online environment, how to manage unique ethical and legal issues related to using technology in therapy and supervision, as well as the effectiveness of therapy and supervision in an online environment (Blumer et al., 2015). From their findings, Blumer and colleagues (2015) called for more training and research of online practices in couple and family therapy, acknowledging that unique advantages likely exist. Now, five years later, these calls are even more pertinent with the expansion of distance-based education programs in mental health professions and the rapid shift to telehealth in response to the COVID-19 pandemic.

Research completed on TS generally shows participants are satisfied by their TS experiences and that it is just as effective as in-person supervision (Bender \& Dykeman, 2016; Tarlow et al., 2020), and that it can contribute to professional identity development (Perry, 2012). When researchers surveyed doctoral student supervisors-intraining $(n=15)$ on their attitudes towards TS, two-thirds responded that they believed in-person supervision was of higher quality than TS, although most participants reported that each type of supervision was equally effective (Inman et al., 2019). Additionally, over half of supervisors-intraining reported building equally strong relationships in both in-person supervision and TS and believed that each type of supervision had a similar influence on supervisee development. About half of participants had similar positive attitudes towards both types of supervision, with most participants reporting they would likely conduct TS in the future (Inman et al., 2019). Bender and Dykeman (2016) found no differences between master's counseling students' perceptions of the effectiveness of traditional 
in-person supervision and their perceptions of the effectiveness of TS. Similarly, a multiple-baseline single case design study of three supervisees who transitioned from in-person supervision to TS found no decreases in supervision satisfaction or supervisory alliance (Tarlow et al., 2020).

Although more information about online practices has been disseminated in the last ten years (e.g., Inman et al., 2019), there is still limited information about best practices for conducting TS to ensure its effectiveness. Studies conducted more than five years ago, may also provide limited relevance as the technology supporting telehealth services in general has substantially evolved in that interval. This limited research does little to calm pervasive skepticism across disciplines about the ability to comprehensively train mental health professionals in an online setting (Chen et al., 2020; Levin et al., 2018; Minton, 2019). Yet, there are some consistent benefits and limitations that have emerged across existing research.

\section{Benefits and Limitations of Telesupervision}

Students often choose online programs for their flexibility, convenience, and/or lack of available programs in their area (Bender \& Dykeman, 2016). This practicality is also a clear benefit of TS, which makes it easier to create the time and space for supervision (Amanvermez et al., 2020; Nelson et al., 2010) and provides access to high quality supervision options (Inman et al., 2019). The technology for easily sharing digital files is another added benefit, which can streamline synchronous viewing of recorded therapy sessions (Nelson et al., 2010). TS offers the opportunity for supervisees and supervisors to interact with one another from their homes, allowing them to see a more human side of one another (Bender et al., 2018). A repeatedly found benefit of TS is that it brings together supervisees across many locations, creating opportunities to learn from one another's diverse backgrounds, training sites, and clients (Inman et al., 2019; Nelson et al., 2010; Perry, 2012). Supervisorsin-training also identified they were just as likely to stay engaged in TS as in-person supervision, with one-third of participants reporting they were more likely to stay engaged in TS than when supervising in-person (Inman et al., 2019). This particular finding aligns with adult education theory which suggests that adult learners are more self-directed and motivated, particularly when instruction is highly relevant to their specific interests and needs (Knowles, 1980). While there are concerns about disengagement in virtual interactions, adult learning theory would suggest that as long as TS is relevant to trainees' needs and is collaborative (1984), they should be able to remain engaged. Adult learners also tend to draw from personal experience in their learning processes (Knowles, 1980), as a result, receiving supervision virtually may help supervisees better understand the experience of teletherapy (Bernhard \& Camins, 2020) and gain mentorship as potential future telesupervisors (Bender et al., 2018).

Limitations of TS are primarily technology based (Inman et al., 2019; Nelson et al., 2010). The nature of video platforms can make it difficult to fully read social cues and understand feedback (Tarlow et al., 2020), which can make assessing clinical skills and implementing feedback challenging (Reicherzer et al., 2012; Inman et al., 2019). Supervisees shared that slow or dropped internet connections were frustrating, and it was easier to be distracted during TS than in-person supervision (Amanvermez et al., 2020). Technological issues may require more time to build supervisorsupervisee rapport (Deane et al., 2015). Ethical issues with not only TS, but with distance-based education in mental health professions have been identified in the literature (e.g., Sheperis et al., 2020). TS-specific concerns relate to navigating ethical codes and laws of supervisees' different locations (Inman et al., 2019), ensuring virtual tools are HIPAA compliant (Cicco, 2014; Deane et al., 2015), and addressing the reality that telesupervisors may not be as readily available as an in-person supervisor to help manage ethical issues (Cicco, 2014).

\section{Effective Telesupervision}

Multiple studies show the supervisor relationship is central to effective TS (Bender et al., 2018; Tarlow et al., 2020), which is also believed to be central to the success of distance-based counselor education programs (Snow et al., 2018; Vincenzes \& Drew, 2017). In one study, students emphasized that TS was successful because supervisors' authenticity created safe relationships where supervisees could be vulnerable (Bender et al., 2018). Despite students' initial skepticism about connecting to their supervisors through an online platform and challenges with technology, many reported building meaningful relationships with supervisors. They found when supervisors helped problemsolve technology issues or at least empathized with them, it strengthened the supervisory relationship (Bender et al., 2018; Tarlow et al., 2020). Counselor educators in distancebased programs also believe that "high expectations, excellent screening, advising and feedback" (p. 141) are critical for program success more generally. It is likely these aspects would be valuable in TS as well.

When providing group TS, it is the supervisor's responsibility to facilitate effective group communication (Tarlow et al., 2020). This involves encouraging supervisees to share experiences and interact with one another, as well as reaching out to supervisees who are experiencing challenges (Chapman et al., 2011; Clark \& Haddock, 2015). To address challenges reading non-verbal cues, telesupervisors should 
encourage the use of verbal descriptions of in-the-moment emotional experiences, attend to verbal cues, provide clear feedback, and check-in with supervisees to ensure accurate understanding of what is communicated (Amanvermez et al., 2020; Clark \& Haddock, 2015). Formal case presentations during group TS can also create opportunities for effective group communication to promote supervisee development (Perry, 2012).

There are several recommendations in the literature on how to build relationships between faculty telesupervisors and student supervisees who have local training sites and supervisors (Cicco, 2014). Faculty supervisors need to assume a role as the overseer of the internship process and coordinate information from multiple sources regarding supervisee's clinical development (Cicco, 2014). As a liaison to local sites and supervisors, they need to open lines of communication early in the process and check in frequently (Perry, 2012). Faculty telesupervisors model respectful, honest communication and maintain a stance of being approachable and easily reachable (Cicco, 2014). They should also be aware of the unique needs and experiences of adult learners who have meaningful life experiences and varying levels of autonomy, all of which will influence their clinical work (Cicco, 2014).

Addressing technological problems is essential to successful TS beyond contributing to the supervisory relationship (Amanvermez et al., 2020). Due to potential for technological failings, alternative plans should be made in advance to prepare for lapses in the availability of tools. Both supervisors and supervisees need to have training and resources available to ensure their ability and comfortability with the online setting (Amanvermez et al., 2020). The importance of adequate technology resources and support is also believed to be central to the success of distance-based programs overall (Snow et al., 2018).

\section{Study Purpose}

At the time of this study, little research has been conducted on TS, and more specifically the use of TS with MFT students. As a result, there is not a clear picture of what it is like for supervisors to promote the unique aspects of MFT training through TS including clinical competencies, a systemic orientation, ethical practice, and DEI. Many studies on TS elicit the valuable perspective of trainees across counselingrelated fields (Bender et al., 2018; Bernhard \& Camins, 2020; Tarlow et al., 2020; Nelson et al., 2010), with fewer studies exploring supervisors' experiences (Inman et al., 2019; Perry, 2012). As supervisors have a deeper understanding of supervision processes and desired outcomes, they will have a rich perspective on what it is like to use TS as a part of a MFT training program. Consequently, the purpose of the current study is to explore faculty supervisors' experiences of providing systemic group TS to MFT students and to identify the perceived benefits and limitations of providing systemic group TS. We hope that in capturing supervisors' experiences we can inform best practices related to providing TS to MFT students for programs that employ this modality.

\section{Methods}

\section{Methodology}

Descriptive phenomenological methods (Giorgi, 2009) were selected to understand faculty supervisors' experiences providing TS. The goal in using this approach is to provide detailed descriptions of supervisors' lived experiences using TS to inform best practices for MFT programs and supervisors who may integrate this method into their work with trainees. We chose descriptive phenomenology because we were interested in the descriptions of experiences, not necessarily the meanings made of those experiences. We followed Giorgi's methods (1985), which are rooted in Husserl's (1970) approach to descriptive phenomenology. Husserl developed a philosophical analysis for exploring consciousness and the objects it is directed towards, which Giorgi then adapted into a method for psychological inquiry. The intention of this method is to "do justice to the lived aspects of human phenomena, and to do so, one first has to know how someone actually experienced what has been lived" (Giorgi, 1985 , p. 1). This quote captures the goal of our research regarding the experiences of supervisors providing TS.

\section{Overview of Group Telesupervision Training}

The university group supervision experience entails connecting with students every week for two hours via a HIPAAcompliant synchronized video platform, which allows supervisees to securely share recordings of therapy sessions as needed to complete assignments. Although a focus of the group is assignment completion, all assignments are connected to the students' experiences of providing clinical services in their local areas. Additionally, there is unstructured time in which students are invited to discuss any cases, concerns, self-of-the-therapist issues, or current events. This differs from an online course experience in that the faculty do not lecture or follow a lesson plan but do ensure assignments are completed and provide resources, as needed.

The group experience at this university is unique. There is not a distinct cohort, as students can start their clinical experience any Monday of the year and are placed in a previously established group. Therefore, students start and leave the groups at different times, thus joining other students at 
different stages within their own clinical experience. For all master's students, the clinical experience is comprised of five clinical courses spanning a minimum of one year. This includes two practicum courses, two internship courses, and a final internship course involving a capstone case presentation. Students engage in their clinical experience after most of their didactic courses are completed, although many students take clinical and didactic courses concurrently. Because the clinical experience lasts at least one year, group members remain reasonably consistent, despite different start times. This allows for ample time to build group cohesion and for each student to hold the role of mentor to new students who start the group after them.

During practicum and internship courses, students are seeing clients at a local site external to the university. The clinical administrative training team supports students in finding a site to complete their clinical experience in their area. Historically, students provided in-person therapy to clients. However, when COAMFTE approved students to provide telehealth services in March 2020, students conducted both in-person and telehealth sessions. Practicum groups include up to six master's students and have a focus of demonstrating basic clinical skills and understanding general systems theory. This demonstration is shown in recorded or live role plays during the two-hour supervision group. Once a student completes their second practicum course, they are moved to an internship group. Internship groups include up to eight master's students and have a focus on developing one's personal model of therapy that is consistent with at least one MFT theory. The assignments in the internship courses include case presentations with recordings of the student engaging in therapy with their clients. Although both practicum and internship groups are mostly comprised of master's students, some groups may include one doctoral student who is enrolled in their doctoral clinical practicum or supervision practicum experience. The faculty supervisor facilitates the group regardless of the student make-up with a focus on course assignments, development as a systemic therapist, and relevant sociocultural issues of the time. All students have a local supervisor who is the supervisor of record and signs off on clinical hours, since students are seeing clients under their local supervisors' licenses.

\section{Participants}

The study involved 18 faculty supervisors currently providing group TS as part of the practicum or internship portion of an online COAMFTE Accredited master's program. All 18 participants were AAMFT Approved Supervisors. Descriptive data was only collected on supervision history for 12 participants who completed individual interviews. Descriptive data was not collected on participants who only completed a focus group. Of the 12 participants who completed an individual interview, they have been AAMFT Approved Supervisors for an average of 5.4 years (1 month-15 years) and have, on average, 4 years (1.5-6 years) of experience as a faculty telesupervisor within the online COAMFTE Accredited program used for this study. Since we recruited from a small population of supervisors at a specific university, further descriptive data are not provided on each participant to protect their confidentiality.

\section{Procedures and Data Collection}

Recruitment materials for the study were sent to all 21 faculty supervisors via email. Those who agreed to participate in the study and provided informed consent had the option of completing a one-hour individual interview and three focus groups with other study participants. They were invited to participate in as many of these opportunities as they desired. As a result, 12 participants completed both an individual interview and at least one focus group, while six participants only joined the focus groups. All data were collected in July and August of 2020.

Individual interviews were semi-structured. They started with a broad inquiry of participants' history providing supervision and general experiences with TS, and then narrowed to explore unique experiences with using TS to promote: a systemic orientation, relationships with and between supervisees, clinical competencies, DEI, and adherence to the AAMFT Code of Ethics. Interviewees were asked if they experienced any unique benefits or limitations in promoting these aspects in the TS format. Phenomenology researchers acknowledge there will always be new information to learn about individuals' lived experience (Vagle, 2018); as a result, interviews ended when we concluded we had a comprehensive understanding of the invariable structure of TS experiences (Giorgi, 2009).

Each of the three focus groups were designed to clarify supervisors' experiences emerging from individual interviews including: general experiences with providing group TS, experiences ensuring group TS remained systemic, and experiences collaborating with local supervisors and the university clinical administrative team in ensuring supervisees' development of clinical competencies. The final focus group reviewed the research team's first draft of core themes to elicit participants' feedback on the congruence of emerging themes and their lived experiences. Focus groups and individual interviews were recorded, transcribed, and analyzed using NVivo qualitative data analysis software. The final themes reported in this paper were refined through both the individual interviews and clarification provided by focus groups. 


\section{Bracketing and Researcher Reflexivity}

In line with descriptive phenomenology methods, we engaged in bracketing our experiences to help prevent our background and interests from impeding our ability to accurately describe the experiences of participants (Giorgi, 1985, 2009). We acknowledge we are faculty and administrators associated with the online program sampled for the present study. As a result, we approached this study with an already established belief that online education and TS methods are effective in training MFT students. There is great likelihood our positions would lead us to look for the benefits of TS and overlook potential limitations. Four of the five researchers were also administrative staff in the university. In order to avoid coercion, the non-administrative researcher served as the primary investigator of the study. She was responsible for soliciting participation and facilitating setting up interviews. However, we cannot ignore that some of the administrative faculty held interviews and this could have influenced participant responses. Informed consent forms reiterated that participation in the study was voluntary and that they could withdraw from the study with no penalty if any discomfort was experienced during their interviews.

All researchers are trained as MFTs, with four of us being AAMFT Approved Supervisors who have provided faculty TS, and one who does not have experience providing supervision. So, those of us who provide supervision acknowledge we have assumptions about what it means to be a systemic supervisor and our own experiences of faculty TS that could influence how we collect and analyze data. Rather than assuming we could turn off our biases, we sought to give them voice and look for ways biases could influence our approach to data collection and analysis so that we could take steps to prevent any negative effects (e.g., member checking). We each engaged in journaling throughout data collection to note any personal reactions to the data collection to help prevent biases from affecting our interviews and data analyses. Some of us observed that our own positive and negative experiences with TS came up during participant interviews, which we processed in our journals and in conversations with one another. We also found that having a detailed guide for the interview, although it remained semistructured, helped us stay on task with specific interview questions and avoid derailment from personal biases.

We found it important to reflect on our personal identities and backgrounds and how they may have influenced/biased the questions we asked and how we interpreted the data. Emily and Cassandra identify as white, heterosexual women living in the Midwest. Tracy identifies as a black CaribbeanAmerican, heterosexual woman residing in South Florida. Rachel identifies as a white, heterosexual woman living in Texas. Darren identifies as a white, heterosexual male residing in Utah. Acknowledging our personal identities is with the intention of recognizing that our identities will give us different experiences of TS. For example, inherently, topics related to racism, homophobia, and other biases inherently arise in supervision and how we experience and respond to these conversations is related to our own identities. Our hope is that acknowledging our personal backgrounds helped us to be mindful to not lead interviewees to affirm our experiences and to create space for sharing of diverse experiences of the TS process, including strengths and limitations. These efforts to limit the negative effect of researcher bias conform to recommendations in the literature (Dahl \& Boss, 2005; Johnson et al., 2020).

\section{Data Analysis}

Data analysis procedures were based on the steps Giorgi (1985, 2009) constructed for analyzing descriptive phenomenological data. Every member of our research team was assigned interview and focus group transcripts to analyze, with at least two of us reviewing each transcript. We approached each transcript by first reading it in its entirety to get a whole picture of the participant's experience of being a faculty telesupervisor. With an attitude of psychological phenomenological reduction (Giorgi, 1985, 2009; Husserl, 1977), through bracketing, we reread each transcript to identify when shifts in meaning occurred. By coding these meaning units, we transformed participant statements into expressions that captured the meanings of the lived experience as a faculty telesupervisor. We met several times to check codes with one another for consistency in coding procedures. Then, coded meaning units were compiled and synthesized using a shared document, which allowed us to identify major themes. This led to a discussion on which meaning units and emerging themes were most salient to faculty telesupervisors' experiences and which meaning units were not part of the essential structure (Giorgi, 2009). After agreeing on core themes, we used them to describe the essential structure of participants' experiences.

\section{Trustworthiness}

Several steps were taken to promote trustworthiness (Guba, 1981). The primary investigator kept an audit trail on major decisions and reflections made throughout the study from its early conceptualization through data collection and analysis. Each researcher also journaled throughout the data collection process to document reactions and biases. Additionally, the final focus group served as a member check to review initial core themes and to help refine our final description of the essential structure of participants' experiences described in individual interviews and previous focus groups. 


\section{Results}

\section{General Experiences with Telesupervision as a Delivery Modality}

Participants described general experiences with TS as a delivery modality. Three subthemes emerged as central to their experience of TS, not specific to the unique role as a faculty supervisor and that would likely transcend many other types of TS outside of a university structure. These subthemes are accessibility, that quality of technology mattered, and intentionality and care promoted supervisee development.

\section{Accessibility}

Participants emphasized that because anyone can join a TS session regardless of physical location, it makes it easier for many potential supervisees to have access. They saw this as especially beneficial for supervisees who have schedule challenges, no brick-and-mortar MFT programs nearby, or who live in rural areas. Participant three explained:

... Physical aspects of supervision can be very challenging for multiple reasons. Whether it's somebody not having a car, not being able to show up because they have kids, because they are single parents ... Online supervision allows opportunities to anyone with internet ... that just expands the richness and the accessibility to people for this field.

We assume accessibility translates to other online programs using TS to reach students in diverse locations and to brick-and-mortar programs who may not be able to meet in person for supervision due to the COVID-19 pandemic.

\section{Quality of Technology Mattered}

Participants described technology as enhancing engagement in the supervision process. Multiple participants highlighted that when the university switched from one synchronous video meeting platform to a newer platform, it enhanced the quality of supervision due to improved connection and additional tools for interacting with supervisees. The share-screen function was one of the most often cited tools participants used. It allowed supervisees to easily share session recordings and supervisors to easily share resources during supervision. Participants also found the chat function provides an additional method for communication during TS. Telesupervisors can privately message students if they have concerns, and the group can use the chat function to add more voices to conversations. Breakout rooms were also used to place supervisees into smaller groups to have more intimate conversations. The whiteboard tool provides opportunities for additional engagement through annotation and illustration (e.g., genograms). The video layout within the platform allows faculty to view all students at once, which can help keep group members focused and assist the supervisor in tracking interactions. Having established virtual relationships also made it easy for telesupervisors to communicate with supervisees using other forms of technology such as e-mail and online scheduling tools.

\section{Intentionality and Care Promoted Supervisee Development}

Faculty supervisors identified TS as effective and satisfying, with some noting they were initially skeptical or uncomfortable with this mode. At the time of the interviews, all participants felt comfortable navigating the technology required to provide TS, although some participants emphasized it took additional work to promote supervisee development via TS due to supervisee disengagement, distractibility, and lack of transparency.

The disengagement and distractibility of supervisees was assumed, as participants noted they were not always aware of what supervisees were doing while logged into the group. The lack of transparency was mentioned as a potential limitation of the TS experience in that supervisees can decide what to show of their clinical work.

The importance of engaging with students to combat disengagement, distractibility, and lack of transparency was emphasized. One participant mentioned not having the ability to spontaneously engage with supervisees outside of TS, since there are no physical office spaces or classrooms that faculty and students congregate around. Additionally, the lack of in-person interactions was identified as a challenge for personal engagement. Participant five explained that:

... Just the physical ... space. You know, if somebody's having a really tough time ... that ability to just put a hand on their arm or hand them a tissue or something like that ... you don't have that. You have to convey that just through your face and your language ... it can be challenging, but also doable.

While technology offers many benefits to the supervision process, technology issues were commonly reported obstacles to engagement in supervision. Challenges included poor internet connection and inexperience or discomfort with using technology. Some telesupervisors also noted it can be more difficult to read group process dynamics in TS in comparison to an in-person group. 


\section{Online University-Specific Experiences with Telesupervision as a Delivery Modality}

Three subthemes emerged that are specific to the experience of the role as a faculty supervisor in this specific online university structure. These subthemes are diversity of students, collaboration of distinct roles within the system, and mindfulness of time within the group supervision session.

\section{Diversity of Supervisees}

As supervisees of this distance-based university could join TS from any location, participants found their TS groups were inherently more diverse. They contrasted this with their own experiences of supervision in the same community and practice setting as their supervisors and peers. The diverse locations and identities of supervisees in TS allowed supervisees to learn from therapists from different backgrounds and from one another's diverse client population. Participants reiterated that having diverse voices in supervision led to richer conversations and learning opportunities regarding systemic practice, clinical competencies, ethics, and DEI.

\section{Collaboration of Distinct Roles within the System}

Participants identified three main entities within the supervisory system that the student interacts with during their clinical experience. This system is comprised of the faculty supervisor, the local supervisor, and the university clinical training administrative team. Most participants talked about the distinct roles of these entities and that all must collaborate for the supervisee's benefit. Faculty supervisors saw their role as educating supervisees about the clinical training process, attending to larger themes and processes, and focusing on overall clinical skills rather than advising on specific cases. Local supervisors were seen to hold more responsibility in guiding supervisees on cases and logistics of client care from a systemic perspective. Finally, the university clinical training administrative team served as policy makers and a resource if there were supervisee issues not remedied after the faculty supervisor addressed it with the supervisee.

In addition to these three entities, participants also mentioned that having multiple faculty supervisors was a resource and benefit of this university. Much like the diversity of students that was discussed throughout the interviews, participants appreciated the diversity of the clinical faculty regarding their physical locations, experiences, and practices. Access is provided to all clinical faculty and the clinical training administrative team during a weekly hour-long synchronous video conferencing session.

\section{Mindfulness of Time}

The other major university-specific theme to emerge from the data was the need to be mindful of how the two hours were spent with the group of supervisees. Participants indicated that the group sessions were curriculum-led, so that there is an increased focus on attending to the structured assignments. Some participants reported the structure of the curriculum could prevent informal clinical conversations, so it was necessary for them to be mindful about creating that time. A few mentioned having a specific agenda or routine they followed during each group session and half of the participants specifically mentioned that the success of TS relied on having both structure and flexibility. Participant 10 shared:

The structure helps me keep things on track and managed, but then sometimes we are doing so much structure that I miss out on just some of the conversation if there's an issue at your site or how are things going.

\section{A Systemic Lens is Intentionally Applied}

Participants described their experiences applying a systemic perspective in the unique context of TS. Related to these experiences, two subthemes emerged emphasizing the importance of building rapport to promote supervisee development and that maintaining a systemic lens in TS is similar to in-person supervision, although it requires more intentionality when responding to supervisees' multiple contexts.

\section{Trust and Rapport}

Faculty emphasized creating trusting relationships with supervisees and between supervisees as key aspects of providing supervision through a systemic lens. Yet, in a virtual context this requires more work and intentionality. Participants noted the importance of curiosity as supervisees learn about one another and orient to both TS and group process. According to participants, emphasis on relationship building is essential to supervisee development across the domains of clinical competencies, ethics, and DEI.

Participants outlined the importance of building rapport with supervisees. This was not more difficult virtually, but it was vital to be authentic and connect intentionally to each supervisee. Each faculty supervisor found unique ways to connect with their supervisees such as by using examples from their own training or meeting with supervisees individually. This intentional rapport building helped to create strong relationships to support supervisees in opening up to the group to share clinical challenges and work on self of the therapist issues. Faculty noticed that nurturing 
relationships with supervisees contributed to closer relationships with local supervisors, increasing the likelihood that local supervisors would communicate concerns about supervisees' development.

Participants shared many strategies for intentionally building relationships between supervisees. This was particularly important with supervisees consistently joining and leaving groups. Most participants described having students formally introduce one another when someone new joined the group. Encouraging supervisees to provide meaningful feedback to each other was also a way one participant worked to deepen bonds between students.

Participants explained the university structure and ease of connecting virtually enhanced collaborative relationships with supervisees and local supervisors. This included having a structured curriculum and policies setting expectations and clear roles for each person involved. For example, regularly scheduled check-in required through the curriculum helped to maintain contact among all parties. Additionally, regular meetings with the clinical administrative team helped trouble shoot problems and identify best practices for collaboration, which in turn enhanced relationships with supervisees and local supervisors. The virtual environment made scheduling all appointments for collaboration easier, resulting in stronger relationships across all systems.

\section{The Same Systemic Lens is Maintained with More Intention}

Faculty reported that in many ways, applying a systemic lens in TS is similar to in-person supervision, however there are more nuances to responding to supervisees' multiple contexts virtually. For example, just like in-person, participants considered how their supervision occurred in a larger set of contexts and encouraged supervisees to adopt common factors of systemic case conceptualization. Participant nine noted, "I always want to make sure that when we're using terms, systemic terms, we're thinking systemically. I'm encouraging them to think systemically by the questions that I ask and try to steer them, encouraging them to use the terms." Additionally, participants' feedback to students centered on their development of systemic therapy models and techniques. Since local supervisors may not have a systemic orientation, participants viewed nurturing a systemic orientation as an essential part of their faculty supervisor role.

Participants described viewing the supervision group as its own system in which they tracked supervisees' interactions, language, and feedback. When problematic interactions occurred, faculty supervisors were intentional about disrupting and redirecting them. Repeatedly, participants explained how the relationships in the supervision group were isomorphic, which underscored the importance of building trusting relationships within the supervision group to encourage supervisees' ability to build trusting relationships with their clients.

Participants shared their efforts to understand each supervisee as part of their own unique local context. This involved attending to the supervisees' local site context, including collaboration with their local site supervisor. They were also cognizant of how current events in supervisees' contexts were influencing them and individual self-of-therapist factors. Participants then considered how supervisees' local contexts interacted with the supervision group as a system, as Participant seven shared:

I' $m$ working with my supervisee considering their contexts and who they are and how they supervise within the context of their work environment, their larger environment, the social, cultural context, but also then their clients, and then their contexts as well. So, I'm looking how all that interacts and then also the interaction of our group members and how that affects what we do, who we are, how we see clients and, and the work we do.

Participants reported it can be difficult to understand supervisees' unique local contexts without physically being in their areas. For example, they may not be aware of policies of the local school system and how an MFT can best collaborate with that system. However, participants reported the virtual nature of supervision enhanced self-of-therapist conversations. The physical distance of being onscreen and not in the room together allowed supervisees to open up and feel safer exploring difficult topics.

Participants shared disappointment related to two common systemic supervision strategies. They noted role-plays were difficult to conduct virtually and live observation was impossible.

\section{Diversity, Equity, and Inclusion are Intentionally Addressed}

Participants described how they consider DEI in their supervision. Although some participants expressed allowing DEI conversations to organically or naturally unfold in group supervision, two areas that were consistent for incorporating DEI conversations were presentations and intentionality.

\section{Presentations}

Participants expressed that course presentations facilitated DEI conversations and current events were often used as launching points for conversations on these topics (e.g., COVID-19, social justice-related incidents and events). Participant two shared about constantly checking in on stereotypes and Participant 10 explained the importance of directly challenging supervisees when they pathologize clients. 
Some participants added that creating safety promotes conversations related to DEI, which leads to intentionality.

\section{Intentionality}

Participants stated they were conscientious about facilitating conversations about DEI-related to clients and group process dynamics. Some participants expressed the importance of the systemic supervisor to bridge the gap in DEI knowledge for all other supervisees. Participant three explained:

I did that a lot around the topic of social justice when things came up. Because I had students with very different perspectives... And so it became an almost recurring topic for maybe three or four weeks where we talked about how each experience, and I tried to give room for each of my students to speak and really express what they felt. And then bring it back to the next person in the room and then use that to think about ways to enhance our systemic lens and understanding ... multiple perspectives and ethics.

Some participants discussed being direct in addressing social justice issues when they arise in TS. Participant five shared about being intentional in lifting the voices of supervisees of color. Some participants found their supervisor role to include a gatekeeping responsibility to address DEIrelated competencies. Participant 10 stated:

I think I particularly have a gatekeeping role around diversity and inclusion. So that ... if there's anything that hints of homophobia, racism or anything like that, I really want to address it pretty directly for everyone's benefit. Not just for that student's benefit, but for everyone in the class seeing that, that will be talked about and addressing it if they didn't have the guts to kind of show a piece of it themselves.

\section{Clinical Competencies and Ethics are Intentionally Addressed}

Participants explained that effectiveness in ensuring students are developing clinical competencies and adhering to the AAMFT Code of Ethics depends on the intentionality of the telesupervisor in addressing directly and repeatedly development of skills in these areas. One way of doing this was to remind students during group supervision of what they learned about core concepts and ethical principles during the didactic portion of their program of study. This included tying these concepts and principles to the supervisee's chosen model and within the developmental level of the student therapist.

Intentionality related to clinical competencies was reflected in what Participant 11 stated, "I haven't followed each case that they might present on. It doesn't mean that they're not developing in these core competency areas. It means that I need to ask questions about them." When asked about ensuring supervisees are adhering to the AAMFT Code of Ethics, Participant nine reported making statements such as, "I want you to pull up the AAMFT Code of Ethics and I want you to find the actual ethical code that we're referencing and we're kind of talking about, okay, read it to me. ... How does that apply to your client and the situation that your client is experiencing?". Viewing recorded therapy sessions also allowed for the telesupervisor to intentionally assess the supervisees development in clinical competencies and ethics, as well as facilitate rich conversations in the group. Participants specifically encouraged students to bring "growth-area" clips to facilitate growth from feedback from the other supervisees and telesupervisor.

Many of the participants added that it is a collaborative effort to ensure development of ethical and competent student therapists. The role of the local clinical supervisor was seen as critical in accomplishing the desired developmental outcomes. Working collaboratively through discussion of planned outcomes in regular meetings involving the supervisee, local clinical supervisor and faculty telesupervisor was reported as being fundamental to success in a model that involves TS groups.

Because TS allows for joining group supervision sessions from any location, participants reported it is critical to consistently remind supervisees of the importance of confidentiality issues. They must be aware of location to ensure no one overhears supervision and closely manage client information that may be transported or stored on a device. Finally, participants reported that it is helpful to include, in addition to the AAMFT Code of Ethics, consistent conversations regarding state regulatory implications related to their practice and to the context of doing virtual supervision.

\section{Discussion}

The study purpose was to capture faculty supervisors' experiences providing TS as part of an online MFT Master's program that has well-established procedures for providing this modality of supervision. Like other studies on TS, our participants feel satisfied by their role as a telesupervisor (Bender \& Dykeman, 2016; Tarlow et al., 2020) and feel connected to their supervisees (Inman et al., 2019). Many of the benefits and limitations of TS participants identified align with those noted in other studies on TS (e.g., Bender et al., 2018; Inman et al., 2019; Nelson et al., 2010) and distance-based education in mental health professions (Sheparis et al., 2020; Snow et al., 2018; Vincenzes \& Drew, 2017). These results illustrate how MFT supervision, typically conducted in-person, can be effectively translated to a virtual 
environment, which can not only inform practices for other online MFT programs, but also support brick-and-mortar programs that have had to quickly switch to TS in response to the COVID-19 pandemic. Collaboration and intentionality are key threads across experiences of ensuring supervisees are developing professional standards of MFT, contributing to the larger literature on best practices for promoting effective TS in MFT programs. Many of the limitations of faculty TS found in our study and others can be addressed through both collaboration and intentionality which can be guided by a larger systemic orientation to supervision. The next sections review clinical training implications, study limitations, and recommendations for future research.

\section{Implications for Clinical Training}

The following implications for clinical training will most directly relate to other online MFT Master's programs that have faculty providing TS to students as part of their practicum and internship requirement. However, brick-andmortar programs who have had to quickly implement TS in response to the COVID-19 pandemic can learn from our experiences utilizing and refining TS with MFT students to avoid a lengthy trial and error process with TS. Additionally, our findings can inform the TS practices of other mental health professional training programs. Based on the limitations and benefits of academic telesupervision, our recommendations for using this approach relate to navigating technology, intentionality, collaboration, and leveraging a systemic perspective.

\section{Navigating Technology}

Considering the opportunities for engagement that technology can provide, along with the challenges, those setting up TS should be conscientious about choosing a platform that promotes seamless connection and offers multiple tools for interacting with supervisees. Based on our findings, as well as those from other studies, faculty telesupervisors should expect that technology-related problems will occur and plan to approach these issues with empathy and technical support rather than punitively (Bender et al., 2018; Tarlow et al., 2020).

\section{Intentionality}

Intentionality was another key take-away from the data. This theme of intentionality was seen in how groups were structured, a systemic lens was applied, and in participants' efforts to address DEI, clinical competencies, and ethics. Clinical course assignments that are presented during group supervision helped to maintain focus on these core pieces of systemic supervision. Additionally, intentionality helps with managing the tendency for supervisees in group TS to get distracted or not participate. Drawing from adult learning theory (Knowles, 1980, 1984), intentional assignments are likely effective in engaging trainees as they keep the learning process collaborative and focused on information that is immediately relevant to practice and life experience.

A major strength of TS present in our study and others is its ability to bring together diverse supervisees and supervisors (Inman et al., 2019; Nelson et al., 2010; Perry, 2012). This is a strength also cited in distance-education as it allows students to learn from one another's experiences and perspectives and widens the pool of available instructors (Inman et al., 2019; Nelson et al., 2010; Perry, 2012; Snow $\&$ Coker, 2020). However, diversity alone cannot promote competencies regarding culturally sensitive practices. How supervisors respond to diverse supervisees and the group dynamics that emerge is critical. Addressing current events related to DEI is an essential component in promotion of competencies and development of the supervisor-supervisee relationship.

The challenge of assessing competencies and ethical practice in clinical programs (Miller \& Springer, 2020) is made more complex when training is provided primarily online; and the literature shows that faculty are concerned about the ability to adequately engage in these tasks virtually (Chen et al., 2020; Levin et al., 2018; Snow et al., 2018). However, this can be done in TS through being intentional about linking previously learned concepts to current clinical practice, collaborating with local supervisors and challenging supervisees to demonstrate competence by applying what they know to their specific client cases. The virtual context also mandates clear modeling of ethical behavior by the faculty telesupervisor, especially related to confidentiality, with the clear expectation that supervisees follow that lead.

\section{Collaboration}

Our findings show it is critical for faculty telesupervisors to collaborate with other parts of the supervisees' training system and that the virtual platform is an asset to facilitating this collaboration. In our participants' unique context, collaboration involved frequently communicating with local supervisors and sites and the clinical administrative team. Because faculty telesupervisors are physically removed from the supervisees' locations, it is important to verify clinical development through other sources, which may vary from trainee to trainee. Based on our findings, Cicco's (2014) recommendations for collaboration between faculty and local supervisors are particularly useful. Faculty telesupervisors are responsible for acting as a liaison with the local site, maintaining open, frequent communication, clarifying roles, and considering the unique needs of adult learners (2014). However, we imagine these strategies would be useful for 
any telesupervisor working with a supervisee who is at a different site than the telesupervisor in order to reduce concerns related to ethical practice.

\section{Leveraging a Systemic Perspective}

The results of our study illustrate a systemic approach to supervision is an asset when managing the dynamics of TS. Primarily, maintaining a systemic perspective promoted relationship building within the supervision group. Deane and colleagues (2015) hypothesized that with technological issues, it might take longer for supervisors to develop relationships with supervisees. Our findings show building relationships does require more effort and care. Strategies for connecting should be authentic to the supervisor, but can include humor, asking questions based on clues from the supervisees' visible environment, meeting one-on-one with students and remaining curious. Our results reiterate that building a supportive environment within the groups enhances the TS experience, as indicated in other studies (Bender et al., 2018; Tarlow et al., 2020). Telesupervisors should be aware that intentional relationship building paired with the physical buffer of meeting virtually may even have the potential for supervisees to feel safer to explore self-oftherapist concerns in comparison to in-person supervision.

Our participants demonstrated how their systemic training helped them capitalize on the unique strengths of TS, as well as more effectively address challenges. As systemic clinicians and supervisors, MFTs are accustomed to considering the many parts of a system not directly visible and skilled at finding ways to make these aspects more overt (Todd et al., 2014). With many aspects of the supervisees' system being out of our direct observation, MFT faculty supervisors can use their systemic training to bring these factors into the TS room.

To summarize, our specific recommendations for academic telesupervisors are:

- Carefully select the platform used for TS.

- Expect and compassionately respond to technical issues.

- Overtly address clinical competencies, DEI, and ethics.

- Initiate communication with local supervisors and maintain frequent contact.

- Take additional time to develop relationships with and between supervisees.

- Maintain a systemic perspective of the supervisee and their context.

These recommendations can each help with relationship building, arguably the most important factor in successful distance-based programs (Snow et al., 2018) and can help to reduce the commonly held concerns about legal and ethical challenges with teaching mental health professionals virtually (Sheperis et al., 2020). Yet, the limitations of our study warrant future research to further refine best practices for TS.

\section{Limitations and Recommendations for Future Research}

All participants in our study are professors in an online program, so they are familiar with navigating interactions virtually. This likely allows them to feel more comfortable and confident in a telesupervisor role. As a result, they may be more likely to feel satisfied by TS experiences than those who have had to transition to TS out of necessity in response to the COVID-19 pandemic. Additionally, all participants in this study are from the same university, therefore their experiences may differ from faculty supervisors in other online programs who could approach clinical training with a different structure.

While faculty supervisors' perspectives are highly critical to understanding the group TS experience of an online MFT program, it would also be valuable to gain supervisees and local supervisors' perspectives on the process. Faculty supervisors were chosen for the present study over student trainees due to their greater understanding of the supervision process in comparison to student trainees. We assumed that supervisors could provide more in-depth information about the benefits and limitations of supervision since they have experience receiving and providing supervision, and as a result understand the purpose and goals of supervision more deeply. We also acknowledge that interviewing faculty supervisors was a more convenient choice over student supervisees or local supervisors, both of which may be more difficult to recruit. With the increased need to understand TS in response to COVID-19, we chose a more convenient sample to generate results most quickly. Despite this, interviewing student trainees and local supervisors about academic TS would provide important perspectives on how it is conducted to inform best practices, particularly to enhance the experience for students and local supervisors. Because our findings were unique to the specific context of an MFT training program, it would also be helpful to conduct a similar study with supervisors providing TS to MFTs post-graduation as they accrue hours for state licensure. Though the findings in this study related to TS were derived from faculty teaching in an online MFT program, they, particularly the best practices shared, could legitimately be applied to other mental health disciplines and can inform distance-based education practices with adults more generally. It also should be noted that our findings on supervisors' perspectives on TS do not capture how supervision in general or TS specifically influences client outcomes. Future research in this area is needed, given the strong emphasis on supervision as a 
primary training tool during and after graduate programs in mental health related fields.

Author Contributions Each author contributed to each stage of the research project, including preparation of study design, data collection, and manuscript composition.

Funding No funding was provided for the study.

Data Availability This data is not publicly available. Semi-structured interview questions are available upon request.

\section{Declarations}

Conflict of interest We have no known conflicts of interest or completing interests to disclose.

Ethical Approval The study was approved by the NCU Institutional Review Board.

Consent to Participate Signed informed consent was provided by all participants.

Consent for Publication Informed consent forms reiterated that results would be used for publication in an academic journal.

\section{References}

AAMFT. (2004). Marriage and family therapy core competencies. Retrieved August 6, 2021, from https://www.coamfte.org/Docum ents/COAMFTE/Accreditation\%20Resources/MFT\%20Core\% 20Competencies\%20(December\%202004).pdf

Amanvermez, Y., Zeren, S. G., Erus, S. M., \& Buyruk Genc, A. (2020). Supervision and peer supervision in online setting: Experiences of psychological counselors. Eurasian Journal of Educational Research, 86, 249-268. https://doi.org/10.14689/ejer.2020.86.12

Bender, S., \& Dykeman, C. (2016). Supervisees' perceptions of effective supervision: A comparison of fully synchronous cybersupervision to traditional methods. Journal of Technology in Human Services, 34(4), 326-337. https://doi.org/10.1080/15228835.2016. 1250026

Bender, S., Rubel, D. J., \& Dykeman, C. (2018). An interpretive phenomenological analysis of doctoral counselor education students' experience of receiving cybersupervision. Journal of Counselor Preparation and Supervision, 11(1), 1-30. Retrieved August 6, 2021, from https://repository.wcsu.edu/jcps/vol11/iss1/7

Bernhard, P. A., \& Camins, J. S. (2020). Supervision from afar: Trainees' perspectives on telesupervision. Counselling Psychology Quarterly. https://doi.org/10.1080/09515070.2020.1770697

Blumer, M., Hertlein, K., \& VandenBosch, M. (2015). Towards the development of educational core competencies for couple and family therapy technology practices. Contemporary Family Therapy: An International Journal, 37(2), 113-121. https://doi.org/10. 1007/s10591-015-9330-1

Chapman, R. A., Baker, S. B., Nassar-McMillan, S. C., \& Gerier, E. R. (2011). Cybersupervision: Further examination of synchronous and asynchronous modalities in counseling practicum supervision. Counselor Education and Supervision, 50, 298-313. https://doi. org/10.1002/j.1556-6978.2011.tb01917.x
Chen, S. Y., Wathen, C., \& Speciale, M. (2020). Online clinical training in the virtual remote environment: Challenges, opportunities, and solutions. The Professional Counselor, 10, 1-12. https://doi.org/10.15241/syc.10.1.78

Cicco, G. (2014). Building effective supervisory relationships in the online counseling course: Faculty and student responsibilities. Journal on School Educational Technology, 10(2), 1-8. Retrieved August 6, 2021, from https://eric.ed.gov/contentdel ivery/servlet/ERICServlet?accno=EJ1097715

Clark, A. A., \& Haddock, L. (2015). Supervision in online counselor and education programs: An account from multiple perspectives. VISTAS Online, 1-13. Retrieved August 6, 2021, from https://www.counseling.org/docs/default-source/vistas/artic le_325c5c21f16116603abcacff0000bee5e7.pdf?sfvrsn=c24a4 $12 \mathrm{c} \_8$

Dahl, C. M., \& Boss, P. (2005). The use of phenomenology for family therapy research: The search for meaning. In D. H. Sprenkle \& F. P. Piercy (Eds.), Research methods in family therapy (2nd ed., pp. 63-84). The Guilford Press.

Deane, F. P., Gonsalvez, C., Blackman, R., Saffioti, D., \& Andresen, R. (2015). Issues in the development of e-supervision in professional psychology: A review. Australian Psychologist, 50(3), 241-247. https://doi.org/10.1111/ap.12107

Giorgi, A. (1985). Phenomenology and psychological research. Duquesne University Press.

Giorgi, A. (2009). The descriptive phenomenological method in psychology: A modified Husserlian approach. Duquesne University Press.

Guba, E. G. (1981). Criteria for assessing the trustworthiness of naturalistic inquiries. Educational Communication and Technology Journal, 29, 75-91. Retrieved August 6, 2021, from http:// www.jstor.org/stable/30219811

Harrison, K. L. (2021). A call to action: Online learning and distance education in the training of couple and family therapists. Journal of Marital and Family Therapy, 47(1), 408-423. https://doi. org/10.1111/jmft.12512

Husserl, E. (1970). The crisis of European sciences and transcendental phenomenology: An introduction to phenomenological philosophy. (D. Carr, Trans.). Northwestern University Press.

Husserl, E. (1977). Phenomenological psychology. Martinus Nijhoff Publishers.

Inman, A. G., Soheilian, S. S., \& Luu, L. P. (2019). Telesupervision: Building bridges in a digital era. Journal of Clinical Psychology, 75(2), 292-301. https://doi.org/10.1002/jclp.22722

Johnson, J. L., Adkins, D., \& Chauvin, S. (2020). A review of the quality indicators of rigor in qualitative research. American Journal of Pharmaceutical Education, 84(1), 138-146. https:// doi.org/10.5688/ajpe7120

Knowles, M. (1980). The modern practice of adult education: Andragogy versus pedagogy. Cambridge Adult Education.

Knowles, M., \& Associates. (1984). Andragogy in action: Applying modern principles of adult learning. Jossey-Bass.

Levin, S., Fulginiti, A., \& Moore, B. (2018). The perceived effectiveness of online social work education: Insights from a national survey of social work educators. Social Work Education, 37(6), 775-789. https://doi.org/10.1080/02615479.2018.1482864

Miller, B. J., \& Springer, P. (2020). Ethics-based training for clinicians: Moving beyond ethical decision-making models. Contemporary Family Therapy. https://doi.org/10.1007/ s10591-020-09537-7

Minton, C. A. B. (2019). Counselor education and supervision: 2017 Inaugural review. Counselor Education and Supervision, 58(1), 4-17. https://doi.org/10.1002/ceas. 12120

Nelson, J. A., Nichter, M., \& Henriksen, R. (2010). On-line supervision and face-to-face supervision in the counseling internship: An exploratory study of similarities and differences. VISTAS 
Online, 1-16. Retrieved August 6, 2021, from https://www. counseling.org/docs/default-source/vistas/vistas_2010_artic le_46.pdf?sfvrsn=7

Nelson, T. S., \& Graves, T. (2011). Core competencies in advanced training: What supervisors say about graduate training. Journal of Marital and Family Therapy, 37(4), 429-451. https://doi.org/ 10.1111/j.1752-0606.2010.00216.x

Perry, C. W. (2012). Constructing professional identity in an online graduate clinical training program: Possibilities for online supervision. Journal of Systemic Therapies, 31(3), 53-67. https://doi. org/10.1521/jsyt.2012.31.3.53

Reicherzer, S., Coker, K., Rush-Wilson, T., Buckley, M., Cannon, K., Harris, S., \& Jorissen, S. (2012). Assessing clinical mental health counseling skills and practice standards in distance education. Counseling Outcome Research and Evaluation, 3(2), 104-115. https://doi.org/10.1177/2150137812452558

Sheperis, D. S., Ordway, A., \& Lamar, M. (2020). Legal and ethical challenges in online counselor education. Professional Counselor, 10(1), 106-119. https://doi.org/10.15241/dss.10.1.106

Snow, W. H., \& Coker, J. K. (2020). Distance counselor education: Past, present, and future. The Professional Counselor, 10(1), 40-56. https://doi.org/10.15241/whs.10.1.40
Snow, W. H., Lamar, M. R., Hinkle, J. S., \& Speciale, M. (2018). Current practices in online counselor education. Professional Counselor, 8(2), 131-145. https://doi.org/10.15241/whs.8.2.131

Tarlow, K. R., McCord, C. E., Nelon, J. L., \& Bernhard, P. A. (2020). Comparing in-person supervision and Telesupervision: A multiple baseline single-case study. Journal of Psychotherapy Integration, 30(2), 383-393. https://doi.org/10.1037/int0000210

Todd, T. C., Storm, C. L., Pierides, K., \& Levy, S. (2014). The complete systemic supervisor: Context, philosophy, and pragmatics (2nd ed.). Wiley-Blackwell.

Vagle, M. D. (2018). Crafting phenomenological research (2nd ed.). Routledge.

Vincenzes, K. A., \& Drew, M. (2017). Facilitating interactive relationships with students online: Recommendations from counselor educators. Distance Learning, 14(4), 13-22.

Publisher's Note Springer Nature remains neutral with regard to jurisdictional claims in published maps and institutional affiliations. 